NEW TRENDS IN FLUID MECHANICS RESEARCH

Proceedings of the Fifth International Conference on Fluid Mechanics, Aug.15-19, 2007, Shanghai, China

(C)2007 Tsinghua University Press \& Springer

\title{
Research on Nozzle Performance in Scramjet
}

\author{
J. P. Li, W. Y. Song, Y. Xing \\ School of Power and Energy, Northwestern Polytechnical University, Xi'an 710072, China \\ Email: lijianping001@mail.nwpu.edu.cn
}

\begin{abstract}
The scramjet is a great potential superiority and has a good prospect in the field of aeronautics and astronautics in the future. The scramjet is composed of inlet, isolator, combustor and nozzle. Nozzle is an important component of the scramjet, which produce thrust. The nozzle performance is related with geometric parameters, free-stream Mach number, flight dynamic pressure, attack angle and the performance of inlet and combustor. The influence of geometric paraneters on the nozzle performance are emphasized by researchers in the world for decades.

In this paperthe verification is made on the nozzle design by both CFD and experiments. The internal flow field of nozzle is simulated by FLUENT. The influence of geometric parameters (divergent angle, nozzle total length, height ratio, and cowl angle) on the nozzle performance is studied. The research conclusions provide instruction for the choice of geometric parameters in the nozzle design.

The results indicate that with the increasing of divergent angle, thrust coefficient $C_{T}$ is increasing; lift coefficient $C_{N}$ is decreasing; pitching moment coefficient $C_{M}$ varies small; with the decreasing of nozzle total length, $C_{T}$ decreases a little; $C_{N}$ and $C_{M}$ decreases distinct. Less total length should be selected prior in condition that ensure the nozzle performance; with the increasing of height ratio, $C_{T}$ increases; $C_{N}$ and $C_{M}$ decreases and the range of $C_{N}$ gets extented; with the increasing of cowl angle, $C_{T}$ is almust constant; $C_{N}$ and $C_{M}$ are decreasing.
\end{abstract}

\section{REFERENCES}

1. Small W J, Weidner J P, Johnston P J. Scramjet nozzle design and analysis as applied to a highly integrated hypersonic research airplane. NASA TND-8334, 1976

2. Shigeya $W$. Scramjet nozzle experiment with hypersonic external flow. Journal of Propulsion and Power, 1993; 9(4): 521-528

3. Tohro M, Shuichi U, et al. Validation studies of scramjet nozzle performance. Journal of Propulsion and Power, 1993; 9(5): 725-730

4. Ryan P. S, Falcon R, Darryll P. Coupled waverider/trajectory optimization for hypersonic cruise AIAA-2005-530

5. Emanuel G. Gas dynamics Theory and Application. New York: AIAA Education Serics. 1986

6. Lee S H, Tohru M. Reactive flow in scramjet external nozzle, AIAA-99-0616 